\title{
Article
}

\section{The Significance of Site of Cut in Self- Harm in Young People}

Gardner, Kathryn Jane, Bickley, Harriet, Turnbull, Pauline, Kapur, Nav, Taylor, Peter and Clements, Caroline

Available at http://clok.uclan.ac.uk/31399/

Gardner, Kathryn Jane ORCID: 0000-0003-3904-1638, Bickley, Harriet, Turnbull, Pauline, Kapur, Nav, Taylor, Peter and Clements, Caroline (2020) The Significance of Site of Cut in Self-Harm in Young People. Journal of Affective Disorders, 266 . pp. 603-609. ISSN 0165-0327

It is advisable to refer to the publisher's version if you intend to cite from the work. http://dx.doi.org/10.1016/j.jad.2020.01.093

For more information about UCLan's research in this area go to http://www.uclan.ac.uk/researchgroups/ and search for <name of research Group>.

For information about Research generally at UCLan please go to http://www.uclan.ac.uk/research/

All outputs in CLoK are protected by Intellectual Property Rights law, including Copyright law. Copyright, IPR and Moral Rights for the works on this site are retained by the individual authors and/or other copyright owners. Terms and conditions for use of this material are defined in the policies page.

\section{CLoK}

Central Lancashire online Knowledge www.clok.uclan.ac.uk

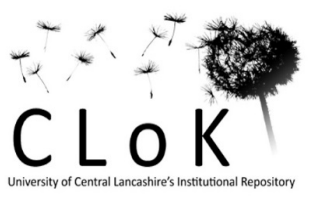




\section{The Significance of Site of Cut in Self-Harm in Young People}

Kathryn Jane Gardner*1, Harriet Bickley ${ }^{2}$, Pauline Turnbull ${ }^{2}$, Nav Kapur ${ }^{2,3}$, Peter Taylor ${ }^{4} \&$ Caroline Clements ${ }^{2}$.

${ }^{*}$ Corresponding author. Kathryn Jane Gardner, School of Psychology, University of Central Lancashire, Preston, Lancashire, PR1 2HE, UK.

${ }^{2}$ Centre for Mental Health and Safety, Division of Psychology and Mental Health, University of Manchester, Manchester Academic Health Sciences Centre, Manchester, M13 9PL, UK.

${ }^{3}$ Greater Manchester Mental Health NHS Foundation Trust, Prestwich Hospital, Prestwich, Manchester, UK

${ }^{4}$ Division of Psychology \& Mental Health, School of Health Sciences, University of Manchester, Manchester Academic Health Sciences Centre. England, M13 9PL, UK. 


\begin{abstract}
Background: Self-cutting in young people is associated with high risk of repetition and suicide. It is important, therefore, to identify characteristics of self-cutting that might impact on repetition and aspects of care by staff. This study aimed to explore differences in clinical (e.g., previous self-harm) and psychological characteristics (intent, mental state, precipitants) of self-cutting in young people based on whether site of cut was visible or concealed.
\end{abstract}

Methods: Data were from a large prospective self-harm monitoring database that collected data on hospital emergency department presentations for self-harm in the City of Manchester, UK, between 2005 and 2011. Clinical and psychological characteristics, as well as onward referral/clinical management from the emergency department, of 799 young people (totalling 1,196 episodes) age 15-24 who self-cut in visible or concealed areas were compared using logistic regression.

Results: During the study period 500 (40\%) episodes were in a concealed location. Concealed self-cutting was more likely to be precipitated by specific self-reported precipitants such as abuse and characterised by the following: previous self-harm, current psychiatric treatment, premeditation, and greater risk of repetition within the study period. Receiving a psychosocial assessment and referral to psychiatric services from the emergency department were less likely, however. Repetition and referral to psychiatric treatment were not significantly associated with site of injury when adjusting for other factors.

Conclusions: There are meaningful differences in characteristics associated with location of cut. We recommend that all young people who present to hospital following self-harm receive a psychosocial assessment, in line with NICE guidance.

Keywords: Self-harm, self-injury. 
Self-harm is an international public health issue (Department of Health, 2017; WHO, 2014) associated with psychological distress (Ferrey et al., 2016) and increased risk of suicidal behaviour (National Confidential Inquiry into Suicide and Safety in Mental Health, 2018; Ribeiro et al., 2016). A recent primary care study found that 12-month repetition of self-harm in young people is common in girls (22.6\%) and boys (18.3\%) and the incidence of self-harm in girls aged 13-16 increased by 68\% between 2011 and 2014 (Morgan et al., 2017). Similar repetition rates for young people have been found in hospital-based studies (17.7\% within 12 months: Hawton, Bergan, Waters et al., 2012), and the incidence of hospital-presenting self-harm is highest in females age 15-24 (Geulayov et al., 2012).

Young people self-harm for a range of reasons (e.g., to regulate distressing emotional states or to communicate distress/the need for support: Taylor et al., 2018), and use a range of methods including self-poisoning and self-cutting (Geulayov et al., 2017). Self-injury by cutting is the second most common method of self-harm seen in the emergency department in adults (Bergen, Hawton, Waters, Cooper \& Kapur, 2010) and adolescents (22\% of presentations involve self-cutting alone: Geulayov et al., 2017). Despite evidence that young people who self-cut are at high risk for repetition of self-harm and suicide (Hawton, Bergen, Kapur, et al., 2012), and that cutting is associated with higher risk of future suicide than selfpoisoning (e.g., Bergen et al., 2012), self-cutting is often seen by clinical staff as a less serious form of self-harm (Kapur, Cooper, O’Connor \& Hawton, 2013). Individuals who selfcut are less likely to receive a full psychosocial assessment or be admitted to a general hospital bed (Kapur et al., 2008; Lilley et al., 2008). Such data suggests that young people who self-cut might be an important clinical subgroup with high clinical risk. However, there has been little work on the specific characteristics of self-cutting such as location of the cut. This is important because clinical management of self-harm depends on an adequate understanding of the behaviour. 
Self-cutting occurs in a variety of locations across the body but is most common on the forearms and wrist (Horrocks, Price, House \& Owens, 2003). There is some albeit limited evidence that choice of location of cut is potentially meaningful for the individual, driven by specific characteristics and/or reflecting suicidal intent and reason/function (Matsumoto et al., 2004). A critical step in advancing our understanding of these issues is identification of the range of characteristics/factors that might distinguish self-cutting in specific areas, such as in visible and concealed locations. This includes: psychological characteristics (e.g. intent behind the self-harm; mental state at the time of self-harm e.g., feeling hopeless); clinical characteristics (e.g. current psychiatric treatment); and immediate precipitating events/problems (e.g., relationship problems: Hawton, Bergen, Waters, et al., 2012; Horrocks et al., 2003; Larkin, Di Blasi, \& Arensman, 2013; Madge et al., 2008). To the best of our knowledge, no prior studies have sought to identify whether these characteristics are correlates of site of cut.

Better understanding of the characteristics that distinguish self-cutting in visible and concealed areas may help inform clinical staff, not least because site of cut might impact clinical management. The potential mechanisms that might explain this relationship could include the assessing practitioner's perceptions of clinical risk (which may mirror the intentrelated differences in young people's perceptions of self-harm in concealed vs. visible areas: Chandler, 2017), and this would be an important target for future research if site of cut is found to be related to clinical management. An important first step, therefore, is to identify whether site of cut is associated with key aspects of clinical management such as referrals to psychiatric services.

Location of self-cutting, whether the site is visible or concealed, may also be informative if it is associated with factors that represent increased clinical risk, such as previous self-harm and repetition which are common in self-cutting (Lilley et al., 2008). 
Moreover, if there are distinguishing features of cutting in concealed and visible locations, it is important to determine the fluidity of location, that is, whether there is a "switch" in location between different episodes of self-harm. Young people who are more reliant on selfharm as a coping mechanism may preference concealed sites as they become wary of others noticing injuries, whereas switching from visible to concealed locations may be influenced by feelings of shame or the reactions of others. Location of self-cutting may therefore change over time or between episodes, in a similar way to switching methods of self-harm (Owens et al., 2015).

Given the need to better understand the significance of location of the cut and the paucity of research in this area, this study aimed to examine potential clinical and psychological characteristics and correlates of site of cutting (concealed or visible) in young people. The specific objectives were:

1) To describe clinical and psychological characteristics of young people based on visible or concealed site of cut.

2) To examine whether site of cut is associated with subsequent clinical management.

3) To examine the association between site of cut and repetition of self-harm.

4) To examine switching between visible and concealed sites of cut.

\section{Method}

\section{The Manchester Self-Harm Project}

Data were from the Manchester Self-Harm Project (manchester.ac.uk/mash). Data capture is comprehensive as the Project collects data on all presentations for self-harm to general hospital emergency departments in the City of Manchester, in the U.K ${ }^{1}$. Self-harm is defined as: 'any intentional self-poisoning or self-injury, irrespective of motivation' (Hawton et al., 2003). Data were collected via two methods. First, full copies of assessments (also known as psychosocial assessments) carried out by psychiatric liaison staff provided by the 
local mental health NHS trust, and/or copies of detailed assessments carried out by Emergency Department clinicians, were provided directly to the Project. Psychosocial assessments of needs and risk includes questions which aim to identify the clinical and demographic features associated with risk of self-harm and/or suicide, and the key psychological characteristics associated with risk e.g., whether the act was premeditated or whether the individual tried to avoid discovery. Second, searches of contemporaneous clinical emergency department patient records provided additional information. Case ascertainment via electronic hospital records was a multi-stage process using extensive and broad search terms (such as, 'laceration,' 'mental health,' 'collapse,' 'arm' and 'stomach problems' etc.) to identify any possible self-harm presentations within triage notes and diagnosis fields. The full hospital record for each presentation where possible self-harm was identified was reviewed, in detail, by an experienced data collector. If the presence of selfharm was confirmed within the notes (which included scans of hand-written clinical notes) data were collected from that record. Based on these two sources of information (psychosocial assessment and clinical records), core data were collected for all cases (i.e. age, gender, details of self-harm presentation - method, time etc.), with additional details only available for those individuals who received a detailed psychosocial assessment (i.e. current mental state, previous self-harm, and current/past psychiatric care etc.).

\section{Case ascertainment for site of cut}

The Manchester Self-Harm Project has been running continuously since 1997. Information on site of cutting was collected as an addition to core data from 2005-2011 inclusive and combined with the core data available for this period, along with data from an additional year (2012) to allow for calculation of a 12-month repetition rate. 
Cases were $\mathrm{N}=799$ adolescents and young adults aged 15-24 ( $M=20, S D=2.60)$ who were included only if cutting was the only method of harm involved. Site of cut was allocated to one of eight possible areas: head, neck, torso, wrist, forearm, rest of arm, leg, and other.

\section{INSERT FIGURE 1 HERE}

\section{Ethics Review}

The Manchester Self-Harm Project is ratified by the National Research Ethics Service, UK. The project is fully compliant with the European Union General Data Protection Regulation (GDPR) 2018, and the UK Data Protection Act 2018. The project also has approval from the Confidentiality Advisory Group (an independent body providing expert advice on the use of confidential patient information) under Section 251 of the National Health Service (NHS) Act 2006 regarding the use of patient-identifiable information in the absence of patient's individual consent. These approvals cover all analyses conducted using the Manchester Self-Harm Project dataset, including the current work.

\section{Analytic Strategy}

A decision rule for determining whether self-harm was 'visible' or 'concealed' was developed based on whether site of cut was more likely to be easily observed by others. Selfcutting was judged visible when the site was head, neck, forearm or wrist. Self-cutting was judged concealed when the site was the leg, torso or the rest of the body. There was a single episode within the sample where site of cutting was classified as 'other' and this was excluded. Further clarification of group designation is included in the discussion.

Analyses were conducted using STATA/IC 15 (StataCorp, 2017). Associations between visible/concealed sites of cutting and key characteristics (e.g., demographics, details 
of self-harm, self-reported precipitants of the episode, clinical impression of intent-related risk factors for suicide and mental state at the time), as well as referral from the emergency department were explored using logistic regression tests. Multivariable logistic regression was used to identify variables associated with referrals alongside other potential predictors that capture severity and intent (previous self-harm, current psychiatric care, clinical impression as to whether the self-harm was premeditated). All episodes were included in the logistic regression analysis. Due to non-independence of episodes belonging to the same individual it was necessary to adjust standard errors to account for this clustering (episodes clustered within people). An episode-based analysis was undertaken as we were interested in the association between site of cut and factors that might change between presentations (e.g. referrals from the emergency department, precipitants, etc.), rather than static characteristics of individuals. A complete-case analysis approach was taken to handle missing data (e.g. where information was missing or 'not known' for a variable, that case was removed from the analysis of that variable).

Self-harm repetition within 12 months was examined by comparing proportions between the two groups. Cox's proportional hazards models explored the influence of location of cut alongside key variables known to be important in repetition (previous selfharm, current psychiatric care, clinical impression as to whether the self-harm was premeditated). This analysis was individual-level with the initial presentation by each individual during the study period followed up for 12 months.

To examine site switching we looked at any changes in site of cut at the following episode after an initial episode with visible or concealed cutting, over the 7-year study period (e.g. not restricted to 12 months). This analysis was episode-level rather than individual level to account for all switching between episodes.

\section{Results}




\section{General Sample Characteristics}

Between 1 January 2005 and 31 December 2011 there were 1,587 episodes where "self-injury by cutting" was the method (20\% of the full dataset for this period). Site of cut was also recorded for $78 \%$ of these episodes, giving a sample of 1,244 episodes. Information on why site of cutting was not collected for some self-harm presentations and the determinants of non-collection was beyond the scope of this study. Chi-square tests were run to identify clinically important and demographic factors that might have influenced whether data were collected. No associations were identified between site of cut and previous selfharm, or between site of cut and demographic factors with almost 100\% complete data (age group, gender, ethnicity).

The mean number of episodes in the sample by individual was 1.43 (SD 1.99) for those with concealed sites of cutting, and 1.24 ( $S D$ 0.95) for those with visible sites of cutting $(t=2.17, d f=1194, p<.05)$.

\section{Characteristics of Individuals who Self-Cut in Visible and Concealed Locations}

Of the 1,244 episodes, $696(56 \%)$ were in a visible site only, $500(40 \%)$ a concealed site only, and $48(4 \%)$ a mix of visible and concealed sites. We analysed only the former two categories and thus the total number of episodes analysed was 1,196. The proportion cutting in visible relative to concealed locations was significantly greater $(t=12.84, d f=3104, p<.01)$. Figure 1 reports the prevalence of self-cutting by area of the body.

The results of the bivariate logistic regression analyses are shown in Table 1. 55\% $(n=383)$ of visible episodes and 44\% ( $n=218)$ of concealed episodes had either a full emergency department assessment or psychiatric assessment and therefore had detailed data available including clinical history, precipitating factors and intent variables (see Table 1 for $\%$ missing data per variable). 
Individuals with a history of previous self-harm, current psychiatric treatment and whose self-harm was premeditated were significantly more likely to cut in a concealed rather than visible location. Regarding precipitants, cutting in concealed locations was significantly more likely in direct response to psychiatric symptoms, for individuals who had been a victim of crime, and for individuals who had experienced physical health problems or abuse (for site of cut and bereavement there was a trend association that fell just short of conventional criteria for significance). Effect sizes varied and were in some cases substantive (e.g., victim of crime).

\section{INSERT TABLE 1 HERE}

\section{Site of Cut and Clinical Management}

Table 2 displays the number and percentage of presentations to EDs following either visible or concealed self-cutting that received specific aspects of care. Episodes where site was concealed were significantly less likely to be referred for psychosocial assessment or referred to psychiatric services from the emergency department (following psychosocial assessment). The association that site of cut had with referrals to psychiatric services became non-significant when included alongside other potential predictors of referrals for psychiatric care (Table 3; it was not possible to examine referrals to psychosocial assessment in this multivariable analysis, since there were dependencies between the outcome and data being available for some predictors).

INSERT TABLES 2 AND 3 HERE 


\section{Repetition (individual level analysis)}

First episodes by individuals, where cutting was in a visible or concealed site, were identified across the study period (the 'index' episode). Five hundred and three people had an index episode where the cut was in a visible site. Of these, $140(28 \% ; 140 / 503)$ had repeat presentations at any time during follow-up, and 106 (21\%; 106/503) repeated within 12 months of the index episode. For people with an index episode of cutting in a concealed site $(n=296)$ there were $108(36 \% ; 108 / 296)$ repeat episodes across the study and follow-up period, and 80 (27\%; 80/296) repeated within 12 months. Concealed cutting was associated with a greater risk of repetition compared to cutting in a visible site (hazard ratio [HR] 1.37, $95 \%$ CI 1.07-1.76, $p=.01$ ) for repetition at any time during the study period, but there was no significant difference between groups in 12-month repetition (HR 0.98, 95\% CI 0.74-1.31, $p=.91)$. Site of injury was no longer significantly associated with repetition within the study period when other key variables were included within the model (Table 4).

\section{INSERT TABLE 4 HERE}

\section{Site Switching}

Across the study period 42\% $(n=293 / 696)$ of episodes with a visible site of cutting were followed by another self-harm presentation by any method. Of these, 49\% ( $n=144 / 293)$ were episodes of self-cutting and site of cut was known. In $56 \%(n=80 / 144)$ of these repeat episodes there was no site switching, while $44 \%(n=64 / 144)$ did switch to a concealed site.

Episodes with a concealed site of cutting were followed by another self-harm presentation using any method 282 times $(56 \%)$. Of these, $54 \%(n=153 / 282)$ were episodes of self-cutting and site of cut was known. In 61\% (n=94/153) of these episodes there was no site switching, whereas $39 \%$ of episodes switched to a visible site $(n=59 / 153)$. 


\section{Discussion}

This novel study examined whether location of cut (visible or concealed) was associated with key clinical/psychological characteristics, repetition and clinical management. Concealed cutting was associated with factors that seemed to represent elevated risk (e.g. repetition, current psychiatric care and history of self-harm). Yet, in our univariate analyses concealed cutting was less likely to lead to both psychosocial assessment and psychiatric aftercare. Self-cutting in visible locations was more frequent overall, but in almost half of repeated episodes there was a switch to a concealed location. Switching from a concealed to visible location was less common (just over $1 / 3$ episodes). However, while switching occurred in both directions stability in location of injury was more common overall. These results emphasise the importance of undertaking a full psychosocial assessment regardless of site of injury to ensure appropriate provision of care for all.

Several factors that may reflect increased clinical risk were associated with concealed cutting, such as previous self-harm and currently being under the care of specialist psychiatric services. These results suggest there are distinguishing characteristics of visible and concealed cutting. If concealed self-harm is associated with greater premeditation alongside a history of self-harm, it may represent an ongoing way of coping rather than a one-off impulsive situational response. As premeditation is present in almost half of all episodes of self-cutting in young people (Madge et al., 2008), this warrants further investigation. Moreover, since other intent-related variables (e.g., suicidal thoughts and plans) were unrelated to site of cut, further research should focus specifically on advancing understanding of the role of intent/motivations for cutting in specific locations.

The possibility that those who conceal self-harm may be more reliant on self-cutting was supported by the finding that the majority did not switch to a visible site (suggestive of a more fixed pattern of behaviour) and that overall repetition of self-harm was significantly 
more common in concealed locations. The twelve-month repetition rate for concealed cutting was elevated compared to visible cutting (and compared to other samples e.g., Hawton, Bergan, Waters et al., 2012), but this was not statistically significant and adjusting for other clinical characteristics suggested that the effect of overall repetition may be due to confounding (e.g. due to overlap with past history of self-harm). Future work should explore associations between location and repetition whilst adjusting for a broad range of potential confounds.

Location of self-cutting was associated with specific self-reported precipitants. Concealed self-harm was more often a direct response to psychiatric symptoms, which in addition to being under current psychiatric care might suggest a broader array of psychological difficulties increases the likelihood of concealed self-harm. Concealed selfharm was precipitated also by exposure to traumatic events including being a victim of crime, experiencing physical health problems, and abuse. The role of abuse/previous trauma in selfharm is especially well-documented (e.g., Ford \& Góme, 2015), but there are many psychological factors associated with self-harm in young people (e.g., Hawton, Kingsbury, Steinhardt, James \& Fagg, 1999) that should be explored in relation to site of cut. Moreover, as numbers for these analyses were small, conclusions remain tentative.

The Manchester Self-Harm Project dataset contains complete cohort-data collected from contemporaneous clinical records, which reduces the risk of recall bias. However, the categorisation of self-cutting episodes as visible or concealed was based on the recorded location of the cut, and not whether the cut was concealed or visible to the clinician at presentation. Sensitivity analyses tested the effect of relocating 'forearm' and 'rest of arm' to the alternative group, as these could potentially be concealed or visible depending on the situation. Results showed that proportions and odds ratios were maintained, and between- 
group differences remained in the same direction (we found only minor changes to some $p$ values); therefore, we retained our original categorisation.

The Project draws on a variety of sources of data collected by clinicians to gather information on individuals presenting at hospital with self-harm, and there is a reliance on clinical judgement, which could lead to inconsistency in how some information is recorded. Moreover, the use of more comprehensive assessment tools that may provide more detailed and psychometrically robust information was beyond the scope of the Project. This limits the ability to test psychological theory and draw conclusions regarding psychological significance, and this is especially true for the assessment of theoretically-pertinent variables where the use psychometric tests (e.g., of intent related variables) would also increase reliability and validity. Future studies should additionally include measures of the functions of/motivations for self-harm (e.g., Klonsky \& Glenn, 2009) as this would significantly advance understanding of whether choice of location is functionally meaningful for the individual (e.g. to communicate distress or regulate emotional states; Taylor et al., 2018). Advantages of the project are that it captures all presentations for self-harm and avoids detection bias since clinicians are blind to the hypotheses that are tested suing the data.

This study used data from individuals who presented to hospital for self-harm and therefore does not capture non-treatment seeking community samples (Geulayov et al., 2017). Self-cutting is more common in young people in the community than in hospital presenting self-harm (Geulayov et al. 2017), and it is possible that characteristics relating to site of cutting may differ within the community population. The majority who cut in concealed or visible sites reported a previous history of self-harm but there is no way to assess methods/sites of cut for these previous episodes. Not capturing this pre-index episode is typical of cohort studies but suggests caution when interpreting our repetition and siteswitching results. 
There is potential also for missing data to impact results, although this was only 0 to $1 \%$ for core variables (age, gender, ethnicity and method of harm etc.) and up to $23 \%$ for variables derived from psychosocial assessments (precipitants, clinical and psychological characteristics etc.). Some results based on smaller numbers were close to statistical significance (e.g., bereavement) and might be significant if replicated with a larger sample. Missing data were overall, not significantly associated with demographic or clinical/psychological variables. However, since individuals with concealed cutting were referred less often for a psychosocial assessment, and the psychosocial assessment was a data source for some study variables, possible bias may have been introduced.

Given the evidence of potentially greater clinical risk (e.g. past self-harm) and psychological difficulty (e.g. history of abuse) in those with concealed self-cutting it is important that individuals receive appropriate psychosocial assessment and adequate clinical management. There was evidence that concealed self-cutting was associated with a reduced likelihood of referral for psychosocial assessment and to psychiatric services, but the relationship with referrals to psychiatric services did not remain significant when adjusting for covariates (it was not possible to adjust for covariates when looking at referral for psychosocial assessment due to collinearity). It is therefore possible that the greater likelihood of current psychiatric treatment (a covariate) in those with concealed self-harm could explain the lower referral rates for this group. We recommend that staff are informed about the potential to underestimate clinical risk when cuts are in certain locations, and the subsequent potential impact on clinical management. The National Institute for Health and Clinical Excellence (NICE) guidance for England and Wales (National Collaborating Centre for Mental Health, 2004) stipulates that all patients presenting with self-harm should receive a psychosocial assessment, yet previous work has identified a range of factors that may impact the care provided to people who self-harm (e.g., the assessing practitioner's previous 
training, knowledge, and attitudes: Karman, Kool, Poslawsky \& van Meijel, 2012) and location of cut may be an additional factor.

Self-harm in young people often does not persist into adulthood (Moran, Romaniuk, Olsson, Borschmann, Carlin \& Patton, 2012), but for adolescents and young adults who selfcut, our findings raise important questions concerning the significance of location of the injury. Future work should seek to understand the functional significance of cutting/repeatedly cutting in a specific location (e.g., by supplementing site of cut data with a psychometric measure of the functions of/reasons for self-harm) and endeavour also to identify why and how location of cut impacts on clinical management (e.g., through clinicians' perceptions of clinical risk). 


\section{References}

Bergen, H., Hawton, K., Waters, K., Cooper, J., \& Kapur, N. (2010). Epidemiology and trends in non-fatal self-harm in three centres in England: 2000-2007. British Journal of Psychiatry, 197(6), 493-498.

Bergen, H., Hawton, K., Waters, K., Ness, J., Cooper, J., Steeg, S., \& Kapur, N. (2012). How do methods of non-fatal self-harm relate to eventual suicide? Journal of Affective Disorders, 136(3), 526-533.

Chandler, A. (2017). Seeking Secrecy: A Qualitative Study of Younger Adolescents' Accounts of Self-harm. Young 26(4), 313-331.

Department of Health. (2017). Preventing Suicide in England: Third progress report on the crossgovernment outcomes strategy to save lives. Retrieved from https://assets.publishing.service.gov.uk/government/uploads/system/uploads/attachment_data /file/582117/Suicide_report_2016_A.pdf

Ferrey, A. E., Hughes, N., D., Simkin, S., Locock, L., Stewart, A., Kapur, N., Gunnell, D., \& Hawton, K. (2016). The impact of self-harm by young people on parents and families: a qualitative study. British Medical Journal Open, 6, 1, e009631.

Ford, J. D., \& Góme, J. M. (2015). The relationship of psychological trauma and dissociative and posttraumatic stress disorders to nonsuicidal self-injury and suicidality: a review. Journal of Trauma and Dissociation, 16, 3, 232-71. doi: 10.1080/15299732.2015.989563.

Geulayov, G., Casey, D., McDonald, K.C., Foster, P., Pritchard, K., Wells, C., Clements, C., Kapur, N., Ness, J., Waters, K., \& Hawton, K. (2017). Incidence of suicide, hospital-presenting nonfatal self-harm, and community-occurring non-fatal self-harm in adolescents in England (the iceberg model of self-harm): a retrospective study. The Lancet Psychiatry, 5(2), 167-174. DOI: $10.1016 / \mathrm{S} 2215-0366(17) 30478-9$. 
Geulayov, G., Kapur, N., Turnbull, P., Clements, C., Waters, K., Ness, J., Townsend E., \& Hawton K. (2012). Epidemiology and trends in non-fatal self-harm in three centres in England, 20002012: findings from the Multicentre Study of Self-harm in England. British Medical Journal Open, 29, 6, 4, e010538. DOI: 10.1136/bmjopen-2015-010538.

Hawton, K., Bergen, H., Kapur, N., Cooper, J., Steeg, S., Ness, J., \& Waters, K. (2012). Repetition of self-harm and suicide following self-harm in children and adolescents: Findings from the Multicentre Study of Self-harm in England. Journal of Child Psychology and Psychiatry and Allied Disciplines, 53(12), 1212-1219. DOI: 10.1111/j.1469-7610.2012.02559.x.

Hawton, K., Bergen H., Waters, K., Ness, J., Cooper, J, Steeg, S., \& Kapur, N. (2012). Epidemiology and nature of self-harm in children and adolescents: findings from the multicentre study of self-harm in England. European Child \& Adolescent Psychiatry, 21, 7, 369-377. DOI: 10.1007/s00787-012-0269-6.

Hawton K., Hall S., Simkin S., Bale L., Bond A., Codd S., \& Stewart A. (2003). Deliberate selfharm in adolescents: a study of characteristics and trends in Oxford, 1990-2000. Journal of Child Psychology and Psychiatry and Allied Disciplines, 44(8), 1191-8.

Hawton, K., Kingsbury, S., Steinhardt, K., James, A., \& Fagg, J. (1999). Repetition of deliberate self-harm by adolescents: the role of psychological factors. Journal of Adolescence, 22(3), 369-78. DOI: 10.1006/jado.1999.0228.

Horrocks, J., Price, S., House, A., \& Owens, D. (2003). Self-injury attendances in the accident and ED: Clinical database study. British Journal of Psychiatry, 183, 34-9.

Kapur, N., Murphy, E., Cooper, J., Bergen, H., Hawton, K., Simkin, S., Casey, D., Horrocks, J., Lilley, R., Noble, R., \& Owens, D. (2008). Psychosocial assessment following self-harm: Results from the Multi-Centre Monitoring of Self-Harm Project. Journal of Affective Disorders, 106(3), 285-293. DOI: 10.1016/j.jad.2007.07.010. 
Kapur, N., Cooper, J., O'Connor, R. C., \& Hawton, K. (2013). Non-suicidal self-injury v. attempted suicide: New diagnosis or false dichotomy? British Journal of Psychiatry, 202(5), 326-328. DOI: 10.1192/bjp.bp.112.116111.

Klonsky, E.D., \& Glenn, C.R. (2009). Assessing the functions of non-suicidal self-injury: Psychometric properties of the Inventory of Statements About Self-injury (ISAS). Journal of Psychopathology and Behavioral Assessment, 31(3), 215-219. doi: 10.1007/s10862-008$9107-\mathrm{z}$

Karman, P., Kool, N., Poslawsky, I.E., \& van Meijel, B. (2015). Nurses' attitudes towards self-harm: a literature review. Journal of Psychiatric \& Mental Health Nursing, 22(1), 65-75. doi: 10.1111/jpm.12171.

Larkin, C., Di Blasi, Z., \& Arensman, E. (2013). Self-cutting versus intentional overdose: psychological risk factors. Medical Hypotheses, 81(2), 347-54. DOI: 10.1016/j.mehy.2013.04.001.

Lilley, R., Owens, D., Horrocks, J., House, A., Noble, R., Bergen, H., Hawton, K., Casey, D., Simkin, S., Murphy, E., Cooper, J., \& Kapur, N. (2008). Hospital care and repetition following self-harm: multicentre comparison of self-poisoning and self-injury. The British Journal of Psychiatry, 192, 440-445. DOI: 10.1192/bjp.bp.107.043380.

Madge, N., Hewitt, A., Hawton, K., Jan de Wilde, E., Corcoran, P., Fekete, S, ...Ystgaard, M. (2008). Deliberate self-harm within an international community sample of young people: comparative findings from the Child \& Adolescent Self-harm in Europe (CASE) Study. Journal of Child Psychology and Psychiatry, 49(6), 667-677. DOI: 10.1111/j.14697610.2008.01879.x.

Matsumoto, T., Yamaguchi, A., Chiba, Y., Asami, T., Iseki, E., \& Hirayasu, Y. (2004). Patterns of self-cutting: A preliminary study on differences in clinical implications between wrist- and 
arm-cutting using a Japanese juvenile detention center sample. Psychiatry and Clinical Neurosciences, 58, 377-382.

Moran, P., Coffey, C., Romaniuk, H., Olsson, C., Borschmann, R., Carlin, J.B., Patton, G.C. (2012) The natural history of self-harm from adolescence to young adulthood: a population-based cohort study, 379(9812), 236-243. Doi.org/10.1016/S0140-6736(11)61141-0.

Morgan, C., Webb, R.T., Carr, M.J., Kontopantelis, E., Green, J., Chew-Graham, C.A., Kapur, N., \& Ashcroft, D.M. (2017). Incidence, clinical management, and mortality risk following selfharm among children and adolescents: cohort study in primary care. British Medical Journal, 359:j4351. DOI:10.1136/bmj.j4351.

National Collaborating Centre for Mental Health. (2004). Self-Harm: The Short-Term Physical and Psychological Management and Secondary Prevention of Self-Harm in Primary and Secondary Care. National Institute for Health and Clinical Excellence: Guidance. NICE Clinical Guidelines, No. 16. British Psychological Society.

National Confidential Inquiry into Suicide and Safety in Mental Health (NCISH). Annual Report: England, Northern Ireland, Scotland and Wales. 2018. University of Manchester.

Owens, D., Kelley, R., Munyombwe, T., Bergen, H., Hawton, K., Cooper, J., Waters, K., West, R., \& Kapur, N. (2015). Switching methods of self-harm at repeat episodes: Findings from a multicentre cohort study. Journal of Affective Disorders, 180, 44-51.

DOI: 10.1016/j.jad.2015.03.051.

Ribeiro, J.D., Franklin, J.C., Fox, K.R., Bentley, K.H., Kleiman, E.M., Chang, B.P., \& Nock, M.K. (2016). Self-injurious thoughts and behaviors as risk factors for future suicide ideation, attempts, and death: a meta-analysis of longitudinal studies. Psychological Medicine, 46, 225-236. 
StataCorp. 2017. Stata Statistical Software: Release 15. College Station, TX: StataCorp LLC.

Taylor, P.J., Jomar, K., Dhingra, K., Forrester, R., Shahmalak, U., \& Dickson, J.M. (2018). A metaanalysis of the prevalence of different functions of non-suicidal self-injury. Journal of Affective Disorders, 227, 759-769. DOI: 10.1016/j.jad.2017.11.073 


\section{Footnotes}

${ }^{1}$ Further information about the Manchester Self-Harm Project can be found at Manchester.ac.uk/mash The Project can be contacted directly for information on data collection and case-ascertainment. 
Table 1: Demographic, clinical and psychological characteristics of self-cutting episodes in a visible and concealed site

\begin{tabular}{|c|c|c|c|c|}
\hline Variable $[\mathrm{n}, \%$ missing] & $\begin{array}{l}\text { Visible } \\
\mathrm{N}=696(\%)\end{array}$ & $\begin{array}{l}\text { Concealed } \\
\mathrm{N}=500(\%)\end{array}$ & OR $(95 \% \mathrm{CI})$ & $p$ value \\
\hline \multicolumn{5}{|l|}{ Demographic characteristics } \\
\hline Female $[0,0 \%]$ & $410(59 \%)$ & $323(65 \%)$ & $0.79(0.59-1.04)$ & .095 \\
\hline Age: $15-17[0,0 \%]$ & $133(19 \%)$ & $87(17 \%)$ & $0.89(0.64-1.23)$ & .490 \\
\hline $18-21$ & $329(47 \%)$ & $224(45 \%)$ & $0.91(0.69-1.18)$ & .462 \\
\hline $22-24$ & $234(34 \%)$ & $189(38 \%)$ & $1.20(0.89-1.62)$ & .237 \\
\hline Ethnicity: White $[102,9 \%]$ & $576(91 \%)$ & $421(91 \%)$ & $1.02(0.58-1.78)$ & .943 \\
\hline Black & $5(1 \%)$ & $5(1 \%)$ & $0.86(0.16-4.74)$ & .861 \\
\hline South Asian & $23(4 \%)$ & $20(4 \%)$ & $1.23(0.57-2.61)$ & .598 \\
\hline Other & $28(4 \%)$ & $16(3 \%)$ & $0.81(0.35-1.89)$ & .625 \\
\hline \multicolumn{5}{|l|}{ Clinical characteristics ${ }^{\mathrm{a}}$} \\
\hline Previous self-harm $[26,4 \%]$ & $298(82 \%)$ & $195(92 \%)$ & $2.51(1.41-4.44)$ & .002 \\
\hline $\begin{array}{l}\text { Alcohol used within } 6 \text { hours of self-harm } \\
{[101,17 \%]}\end{array}$ & $151(48 \%)$ & $73(40 \%)$ & $0.72(0.48-1.09)$ & .121 \\
\hline $\begin{array}{l}\text { History of psychiatric treatment }[81, \\
13 \%]\end{array}$ & $194(59 \%)$ & $128(67 \%)$ & $1.41(0.94-2.12)$ & .093 \\
\hline Current psychiatric treatment $[84,14 \%]$ & $147(45 \%)$ & $125(65 \%)$ & $2.31(1.56-3.40)$ & $<.001$ \\
\hline Current alcohol misuse $[110,18 \%]$ & $68(22 \%)$ & $40(23 \%)$ & $1.18(0.75-1.88)$ & .474 \\
\hline Current substance misuse $[105,17 \%]$ & $65(21 \%)$ & $34(19 \%)$ & $0.90(0.57-1.43)$ & .653 \\
\hline \multicolumn{5}{|l|}{ Psychological characteristics ${ }^{\mathrm{a}}$} \\
\hline Self-harm was premeditated $[128,21 \%]$ & $37(12 \%)$ & $36(21 \%)$ & $1.95(1.15-3.32)$ & .013 \\
\hline Tried to avoid discovery $[137,23 \%]$ & $19(6 \%)$ & $14(8 \%)$ & $1.33(0.63-2.80)$ & .461 \\
\hline Wanted to die $[130,22 \%]$ & $95(32 \%)$ & $46(27 \%)$ & $0.77(0.51-1.18)$ & .237 \\
\hline Patient feels depressed $[50,8 \%]$ & $214(61 \%)$ & $136(68 \%)$ & $1.36(0.92-2.01)$ & .123 \\
\hline $\begin{array}{l}\text { Clinician assessment of depression }[60, \\
10 \%]\end{array}$ & $141(41 \%)$ & $96(48 \%)$ & $1.33(0.92-1.93)$ & .133 \\
\hline Hopelessness $[77,13 \%]$ & $110(33 \%)$ & $75(39 \%)$ & $1.33(0.92-1.92)$ & .134 \\
\hline Suicidal thoughts $[44,7 \%]$ & $144(41 \%)$ & $96(47 \%)$ & $1.27(0.89-1.82)$ & .189 \\
\hline Suicide plans $[53,9 \%]$ & $50(14 \%)$ & $28(14 \%)$ & $0.94(0.57-1.56)$ & .822 \\
\hline \multicolumn{5}{|l|}{ Problems Precipitating self-harma } \\
\hline Relationship problems (all) $[71,12 \%]$ & $214(64 \%)$ & $118(61 \%)$ & $0.89(0.61-1.28)$ & .521 \\
\hline Bullying/intimidation $[71,12 \%]$ & $17(5 \%)$ & $14(7 \%)$ & $1.46(0.71-2.98)$ & .299 \\
\hline Bereavement $[71,12 \%]$ & $22(7 \%)$ & $22(11 \%)$ & $1.83(0.98-3.41)$ & .059 \\
\hline Housing problem $[71,12 \%]$ & $34(10 \%)$ & $25(13 \%)$ & $1.31(0.77-2.25)$ & .320 \\
\hline Employment or study problem $[71,12 \%]$ & $50(15 \%)$ & $34(18 \%)$ & $1.22(0.76-1.93)$ & .410 \\
\hline Legal problem $[71,12 \%]$ & $20(6 \%)$ & $13(7 \%)$ & $1.13(0.54-2.38)$ & .738 \\
\hline Victim of crime $[71,12 \%]$ & $8(2 \%)$ & $17(9 \%)$ & $3.94(1.74-8.89)$ & .001 \\
\hline Physical health problem $[71,12 \%]$ & $5(1 \%)$ & $11(6 \%)$ & $3.98(1.36-11.64)$ & .012 \\
\hline Financial problem $[71,12 \%]$ & $28(8 \%)$ & $10(5 \%)$ & $0.60(0.28-1.27)$ & .180 \\
\hline
\end{tabular}




\begin{tabular}{lllll}
\hline Variable [n, \% missing] & $\begin{array}{l}\text { Visible } \\
\mathbf{N = 6 9 6}(\%)\end{array}$ & $\begin{array}{l}\text { Concealed } \\
\mathbf{N = 5 0 0}(\%)\end{array}$ & OR (95\% CI) & $\boldsymbol{p}$ value \\
\hline $\begin{array}{l}\text { Direct response to psychiatric symptoms } \\
{[71,12 \%]}\end{array}$ & $41(12 \%)$ & $40(21 \%)$ & $\mathbf{1 . 8 7}(\mathbf{1 . 1 5 - 3 . 0 5 )}$ & .012 \\
$\begin{array}{l}\text { Alcohol misuse/abuse [89, 15\%] } \\
\text { Substance misuse/abuse [89, 15\%] }\end{array}$ & $19(13 \%)$ & $26(14 \%)$ & $1.08(0.63-1.86)$ & .780 \\
$\begin{array}{l}\text { Abuse (physical, sexual or psychological) } \\
{[71,12 \%]}\end{array}$ & $22(7 \%)$ & $34(18 \%)$ & $\mathbf{3 . 0 3}(\mathbf{1 . 7 2 - 5 . 3 5 )}$ & $<.001$ \\
\hline
\end{tabular}

Notes. Missing data varied from 0 to $23 \%$ per variable. This is based on all cases for the demographic variables, but only on assessed cases for all the other variables. Outcome coded as $1=$ concealed, $0=$ visible. Significant confidence intervals re in bold.

${ }^{a}$ Only episodes resulting in a psychosocial assessment.

Table 2: Clinical management after presentation to the emergency department for selfcutting episodes in a visible or concealed site

\begin{tabular}{lllll}
\hline Variable [n, \% missing] & $\begin{array}{l}\text { Visible } \\
\text { N=696 (\%) }\end{array}$ & $\begin{array}{l}\text { Concealed } \\
\mathbf{N = 5 0 0}(\boldsymbol{\%})\end{array}$ & OR (95\% CI) & $\begin{array}{l}\boldsymbol{p} \\
\text { value }\end{array}$ \\
\hline Psychosocial assessment [0,0\%] & $383(55 \%)$ & $218(44 \%)$ & $\mathbf{0 . 6 3}(\mathbf{0 . 4 9 - 0 . 8 2})$ & $<.001$ \\
Referral to psychiatric services [30,3\%] & $251(40 \%)$ & $142(33 \%)$ & $\mathbf{0 . 7 5 ( 0 . 5 6 - 0 . 9 9 )}$ & .042 \\
Self-discharge [30,3\%] & $20(3 \%)$ & $21(5 \%)$ & $1.56(0.83-2.94)$ & .160 \\
General hospital admission [35,3\%] & $60(10 \%)$ & $39(9 \%)$ & $0.95(0.60-1.51)$ & .827 \\
\hline
\end{tabular}

Notes. Missing data varied from 0 to $3 \%$ per variable, based on all cases. Outcome coded as $1=$ concealed, $0=$ visible. Significant confidence intervals are in bold.

Table 3: Multiple-variable models for referrals to psychiatric services

\begin{tabular}{lcc}
\hline Variable $^{\mathrm{a}}$ & OR $(\mathbf{9 5 \%} \mathbf{C I})$ & $\boldsymbol{p}$ value \\
\hline Concealed cutting & $0.86(0.55-1.35)$ & .514 \\
Previous self-harm & $1.23(0.70-2.16)$ & .482 \\
Current psychiatric treatment & $1.14(0.75-1.73)$ & .535 \\
Self-harm was premeditated & $1.25(0.73-2.16)$ & .415
\end{tabular}

Notes. Outcome coded as $1=$ referral to psychiatric services, $0=$ no referral. Variables were included based on established associations with aspects of clinical management. Significant confidence intervals are in bold (none present).

${ }^{\text {a }}$ Missing data varied from 0 to $21 \%$ per variable, based on assessed cases only. 
Table 4: Multiple-variable cox regression model for repetition of self-harm within 12 months and within the study period

\begin{tabular}{lcccc}
\hline Variable $^{\text {a }}$ & \multicolumn{2}{c}{$\begin{array}{c}\text { Repetition within } 12 \\
\text { months }\end{array}$} & \multicolumn{2}{c}{$\begin{array}{c}\text { Repetition within study } \\
\text { period }\end{array}$} \\
\hline & HR (95\%CI) & $\boldsymbol{p}$ value & HR (95\%CI) & $\boldsymbol{p}$ value \\
\hline Concealed cutting & $1.07(0.68-1.67)$ & 0.78 & $1.18(0.78-1.80)$ & .432 \\
Previous self-harm & $1.00(0.27-3.74)$ & 1.00 & $\mathbf{2 . 7 1}(\mathbf{1 . 3 1 - 5 . 6 1})$ & .007 \\
Current psychiatric treatment & $1.44(0.91-2.27)$ & 0.12 & $\mathbf{1 . 6 4}(\mathbf{1 . 1 0 - 2 . 4 5 )}$ & .015 \\
Self-harm was premeditated & $0.82(0.38-1.75)$ & 0.61 & $1.17(0.66-2.05)$ & .596 \\
\hline
\end{tabular}

Notes. Clinical and psychological variables significant at $\mathrm{p} \leq 0.05$ in the univariate analysis were included. Significant confidence intervals are in bold.

${ }^{a}$ Missing data varied from 4 to $21 \%$ per variable, based on assessed cases only. 
Figure 1: Prevalence of self-cutting by area of the body

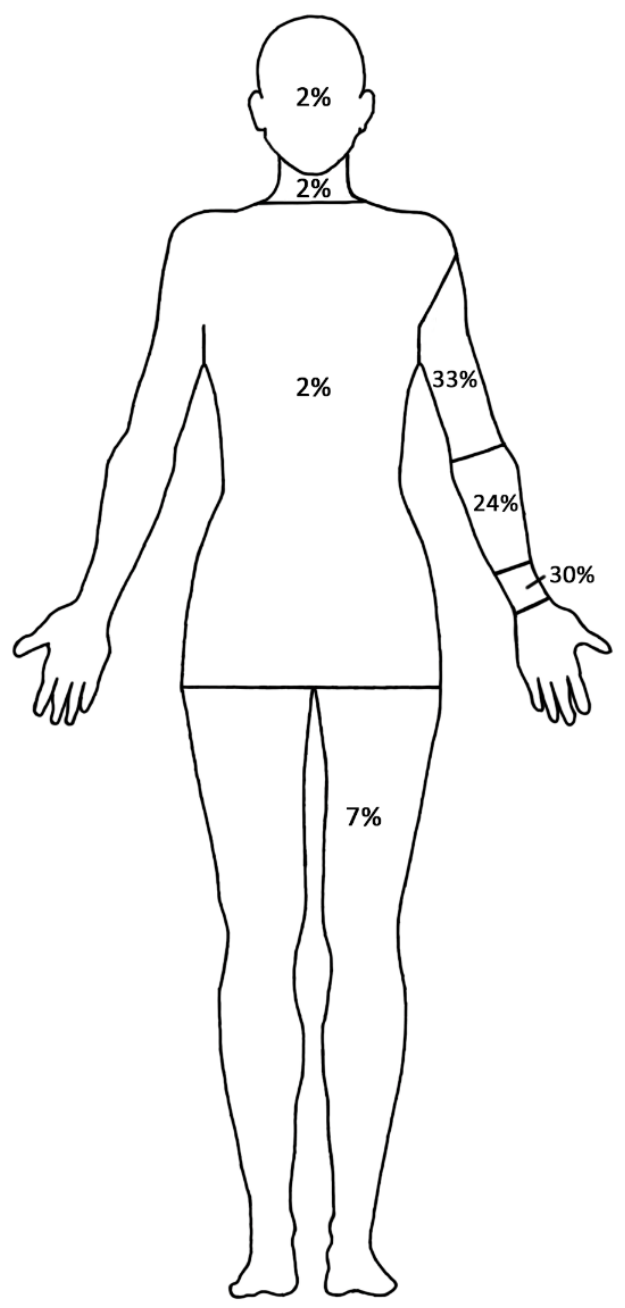

